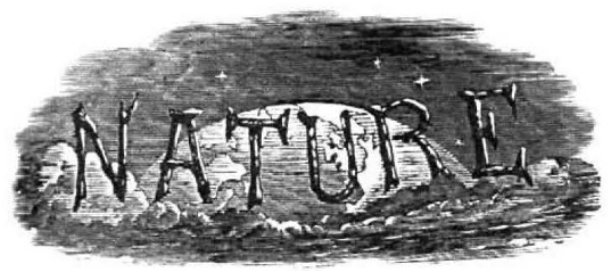

SATURDAY, JULY 29, I923.
PAGE

Large Scale Research in Abstract Science. By Sir R. T. Glazebrook, K.C.B., F.R.S. . . . I2I An Epitome of Antarctic Adventure. By F. Debenham 123 The Physics of the X-Rays. By Dr. G. W. C. Kaye I25 Elementary Zoology . . . I26 Arabia and Arab Alliances. By Sir T. H. Holdich, K.C.M.G. .

Our Bookshelf.

Letters to the Editor:-

The Quantum in Atomic Astronomy.-Sir Oliver Lodge, F.R.S.

The Resolving Power of Microscopes on Test-plates for Microscopic Objectives. (With Diagrams.)A. Mallock, F.R.S.

The Fluorescence of certain Lower Plants.-Prof. Francis E. Lloyd . • • • • • 132 Dr. Kammerer's Lecture to the Linnean Society.J. T. Cunningham . . . . . . The British Journal of Experimental Biology:-Dr.

F. A. E. Crew, Prof. W. J. Dakin, and Others An Einstein Paradox.-J. T. Combridge . . Multiple Temperature Incubator.-C. B. Williams Phosphorescence caused by Active Nitrogen.-Dr. H. Krepelka .

The Cryogenic Laboratory of the University of Toronto. (Illustrated.) By Prof. J. C. McLennan, F.R.S. .

Rickets in Vienna $\cdot{ }^{\circ} \cdot{ }^{\circ} \cdot$

Current Topics and Events $\quad . \quad$. $\quad . \quad \cdot 140$

Our Astronomical Column . . . . . I43

Research Items $\quad$. $\quad$ • $\quad$. 144

Problems of Fundamental Astronomy. By Prof. W. de Sitter . • • . . . . . 147 Night Temperature on Mt. Etna. By L. C. W. B. 149 The School of Hygiene in London • • • . 149 University and Educational Intelligence . . . 149 Societies and Academies . . . . . . I5I Official Publications Received . • . . . 152 Recent Scientific and Technical Books . . Supp. iii.

Editorial and Publishing Offices:

MACMILLAN \& CO., LTR

ST. MARTIN'S STREET, LONDON, W.C. 2.

Advertisements and business letters should be addressed to the Publishers.

Editorial communications to the Editor.

Telegraphic Address: PHUSIS, LONDON.

Telephone Number: GERRARD 8830.

\section{Large Scale Research in Abstract Science.}

CEVERAL recent lectures and addresses have given $\checkmark$ prominence to the interconnexion between abstract science and industry and the marked influence of science on industrial progress. Among these may be mentioned two addresses by Sir J. J. Thomson, the first at the opening of the new laboratories of the General Electric Company at Wembley and the second from the chair as president of the Institute of Physics, the James Forest lecture of the Institution of Civil Engineers, and, most recent of all, the fourteenth Kelvin lecture of the Institution of Electrical Engineers by Prof. J. A. Fleming.

Prof. Fleming deals with problems in telephony, solved and unsolved, and illustrates in a remarkable way and with great knowledge and insight the consequences of scientific inquiry in the past, and the need for further researches in the future. Graham Bell died last year; Kelvin in 1876 had returned from the American Centennial Exhibition at Philadelphia to take the chair of Section A of the British Association at Glasgow, full of the invention of the telephone, which he described in his own inimitable manner, and Prof. Fleming, who forty-six years ago had been one of his audience at Glasgow, writes :

"In the year, therefore, following that of the decease of the illustrious inventor of the speaking telephone it is perhaps appropriate that the Kelvin Lecture should direct attention to some of the problems of telephony which have been solved or which remain unsolved."

The solved problems are sufficiently wonderful; the amplitude of the air vibrations in a just audible sound varies from about $10^{-8} \mathrm{~cm}$. at a frequency of (say) $25^{6}$ to rather more than IO $^{-11} \mathrm{~cm}$. at the highest audible frequencies, and minute motions such as these are impressed on the telephone diaphragm, translated into the variations of an electric current, transmitted to a distance, there amplified, communicated to the receiver, and from it to the observer's ear. Fleming's Kelvin lecture is a fascinating story of the many steps by which this has been achieved, showing how by degrees workers in various lands have each contributed their quota to the advance and made speech possible over 2000 or perhaps 3000 miles by aerial lines, 500 miles by underground, and 200 miles by submarine cables.

This progress rests on the theoretical investigation by Heaviside of the conditions for undistorted transmission, the application of this work, with successive improvements, by Pupin and Krarup and others to the loading of cables and the advances available by the use of the thermionic valve as an amplifier

No. 2804 , voL. I 2$]$ 
and as the originator of "carrier" waves, rendering possible multiple telephony.

For the application of the valve as a rectifier of electric currents, we have to thank Fleming himself, while its whole action depends on the properties of the electron and the discoveries of J. J. Thomson. By the use of the valve as a repeater, many ingenious relays, the outcome of long and difficult investigations, have been placed in a secondary position; the lecturer explains in some detail how, by the selection of the suitable part of its characteristic curve, variations in the grid voltage can be impressed on the plate current and amplified by a transformer, while if another portion of the characteristic be employed, carrier wave multiple telephony is realised. In this "frequency filters " are employed—short circuits containing capacity and inductance which allow only those currents in which the frequency lies between certain limits to enter the line. The broad principles of the method are outlined thus :

"At one end of an existing long-distance telephone. line used in the ordinary way for telephonic speech we can attach a certain number of modulating valves with their plate circuits coupled to the line with their appropriate transformers and filters. We can then generate by means of a number of oscillating valves high frequency currents of certain different frequencies and apply the electromotive forces due to these in series with the electromotive forces of low or speech frequency produced by ordinary carbon microphone transmitters so as to give to the grids of the several modulating valves carrier frequency plus voice frequency voltages. At the receiving end we separate out the several groups of oscillations by suitable band filters and apply the electromotive forces produced by suitable transformers to the grids of demodulating valves. In the plate circuits of these last valves we have coupled ordinary telephone receivers actuated by the voice currents disentangled by these demodulating valves from their respective carrier circuits."

Such has been the progress of less than fifty years. Fleming asks somewhat despondingly what is being done now in Great Britain. He refers to the laboratories of the great technical corporations of the United States, the American Telephone and Telegraph Company, the Western Electric Company, and the General Electric Company, giving an account of their activities in almost the same terms as those employed by Sir J. J. Thomson in his address to the Institute of Physics. "They retain," he writes, "the services of scientific investigators of the highest ability, who direct their attention not exclusively to problems of immediate commercial advantage, but look far ahead into the possible requirements of the future." Sir J. J. Thomson described two of these laboratories as seen by him during his recent visit to the United States.
He found men at work on the most abstruse questions of physics-one need only mention Langmuir and the properties of the atom, or Coolidge and the investigations which led to the development of the Coolidge tube. There were numerous staffs of skilled assistants, some no doubt engaged in solving conundrums put to them by puzzled works managers, but many others searching deep into the secrets of Nature in the endeavour to find out new truths and to advance natural knowledge. Funds were practically unstinted, for the business directors of the works had found that by this means only could they extend the sphere of their activities and provide the dividends called for by their shareholders. In the United States abstract science has been made to pay.

Or to turn to another subject and another speaker. Quite recently the Wilbur Wright lecture, established by the Royal Aeronautical Society in memory of the American pioneer of aviation, was delivered in London by Prof. Ames, of the Johns Hopkins University. Prof. Ames is the chairman of the Executive Committee of the National Advisory Committee for Aeronautics of the United States, and directs the experimental work-full scale and model-of that committee at Langley Field. He has realised very fully the importance of an accurate knowledge of the air pressures on any part of aircraft undergoing manœuvres in the air; we were well aware of this, and years ago had done model experiments at the National Physical Laboratory, while at Farnborough apparatus for use in the air had been devised and some few experiments made. Prof. Ames showed slides illustrating in a most striking way the results obtained both on aeroplanes and airships, leading to information in the case of the latter which the Aeronautical Research Committee has pressed for many times, and which, had it been available in time, should have prevented the accident to the British airship $R_{3} 8$.

Nor is this all : instruments have been successfully constructed which permit all the elements which contribute to a knowledge of the flight of an aeroplaneits velocities, accelerations, and the stresses to which its various parts are subject in the air-to be recorded during its flight. Instruments corresponding to some of these, such as the quartz-fibre accelerometer or the control force measuring stick, have been in existence at the Royal Aircraft Establishment for years ; instruments corresponding to all have been planned and are in various stages of construction. In the United States they have found a man gifted with the knowledge to realise their need and with the authority to give effect to his knowledge. In England we have lagged behind.

So it is in other subjects; Great Britain is a small country, it is true, compared with the United States.

NO. 2804 , VOL. I I 2$]$ 
We owe much-in more senses than one-to our transatlantic kinsfolk, and we are piling up a debt which will prove more serious than the millions of the funding loan. What are we doing, what can we do, to reduce the load, to equalise the position ?

The General Electric Company has its new laboratories at Wembley finely equipped and guided in the proper spirit. "The question," Mr. Paterson writes, "is sometimes asked whether the laboratories undertake pure research or confine themselves to applied research," and his answer is that "the question is meaningless." "A research laboratory," he holds, "is not complete unless it contains members interested in almost every branch of science and provides facilities for these and also for other classes of work."

The National Physical Laboratory devotes much of the energy of its staff to abstract science, though telegraphy and telephony have not figured largely in its programme ; these are catered for to some extent by the Post Office Research Laboratory at Dollis Hill. For metallurgical work we have the Brown Firth research laboratories and the Hadfield Laboratory at Sheffield; other firms have laboratories in which occasionally an investigation in pure science is carried out. But as a rule a work's laboratory is mainly occupied in controlling the normal product of the works, testing the materials supplied, and assisting the works managers in maintaining a proper standard.

Then there are the laboratories of the Research Associations established and in part financed by the Department of Scientific and Industrial Research; good and valuable work is being done by these, but the co-operative system has its obvious disadvantages, and in but few is abstract science pressed very far.

Our best hope for the future would seem to be with the universities, but here again the want of funds is an almost fatal handicap. "There is not," writes Prof. Fleming, " as far as I am aware a single university in this country which possesses the necessary equipment for conducting advanced experimental research in telephony and telegraphy"; and this is true of many other subjects.

Research is terribly expensive. We have always had men of the highest scientific originality who in the past have been pioneers in the advance of knowledge; we have them still, but somehow we fail to estimate their value; we are reluctant to furnish them with the means alone by which their natural gifts may be utilised. The application of science can be organised, and many steps have been taken in recent years to improve its organisation, but if we wish to utilise scientific progress to prevent waste and to increase the efficiency of industry we must support the solitary genius working often for a mere pittance in some university or college laboratory and devoting all his powers to unravelling a little further the tangled skein of Nature's mysteries. Success in the struggle depends on finding the right man and in affording him full facilities. We have the men; will our legislators who control the nation's purse see that facilities are not wanting for their work ?

R. T. Glazebrook.

\section{An Epitome or Antarctic Adventure.}

The Life of Sir Ernest Shackleton, C.V.O., O.B.E. (Mil.), LL.D. By Hugh Robert Mill. Pp. $\mathrm{xv}+3 \mathrm{I} 2+20$ plates. (London: William Heinemann, Ltd., I923.) 2Is. net.

B common consent, Dr. Hugh Robert Mill, the author of "The Siege of the South Pole" and the friend and adviser of a generation of polar explorers, must be acclaimed the right man to tell us the story of the most brilliant career in modern Antarctic exploration. Not only has he long been the ablest chronicler and the most sympathetic critic of adventure and achievement in the southern seas, but he was also for long the friend and oftentimes the confidant of the subject of this biography. It was, therefore, with the keenest anticipation that we took up the book, anxious to see how a master hand would deal with a life so full of light and shade and a character compounded of such contrary impulses. The result is somewhat of a revelation, and whatever may be said in criticism of the book it must be acknowledged that the biographer has carried out his task worthily and has revealed to us the man as he was, fully and fairly. It was obviously no light task to reconcile the leader of magnificent sledge journeys with the unsuccessful dabbler in city finance, the platform lecturer, unconventional even to bluntness, with the sensitive lover of poetry, but it has been done with skill and understanding and the result will be to many a new Shackleton, undreamt of by those who knew but one of his many aspects.

The book is divided into three sections corresponding with somewhat indefinite periods in the life. In the first, styled "Equipment," we are introduced to a healthily mischievous boy with a taste for poetry and the sea, developing along normal lines into an efficient but scarcely an enthusiastic officer of the mercantile marine. So far the story is an ordinary one, and even to Dr. Mill's discerning eyes it foreshadows but little of the future. But then appears the nucleus round which his energy and ambition gathered. To the average reader the story becomes alive immediately

No. 2804 , vOL. I I 27 